\section{A Spatial Distribution Analysis on the Deposition Mechanism Complexity of the Organic Material of Kidney Stone}

\author{
Warty Y. ${ }^{* \bullet}$, Haryanto F. ${ }^{2}$, Fitri L. A ${ }^{1}$, Haekal M. ${ }^{2}$, Herman H. ${ }^{3}$
}

\begin{abstract}
Background: Kidney stones in the urinary system are formed from complex minerals that can interfere with the function of the kidney. This formation occurs gradually and can be observed from the appearance of the kidney stones cross-section which are cut along its longitudinal axis resembling a tree cambium. A deeper study on the composition of these layers will provide etiological and pathophysiological information on the mechanism of the formation and development of kidney stones. In addition, an accurate analysis on the composition of the kidney stone can provide a scientific basis to determine the choice of medical treatment and efforts to prevent from forming of kidney stones in humans.
\end{abstract}

Objective: This study aimed to analyze the organic material that makes up kidney stones in each layer.

Material and Methods: In this analytical study, the components and morphological properties of five kidney stones in each layer were characterized using Fourier transform infrared-attenuated total reflection (FTIR-ATR) and Scanning Elecron Microscope-Element Distribution Analysis (SEM-EDS).

Results: FTIR-ATR displayed the typical absorption peaks for each stone constituent component. The components of each layer showed the same peak value for each absorption peak which consisted of calcium oxalate monohydrate, struvite, ammonium ion calcium oxalate monohydrate, calcium oxalate monohydrate-calcium phosphate and uric acid. Meanwhile, the difference in the percentage and composition of the elements in each stone can be observed by SEM-EDS.

Conclusion: From this study, it can be concluded that each layer of the kidney stones has a different percentage and composition of elements.

Citation: Warty Y, Haryanto F, Fitri LA, Haekal M, Herman H. A Spatial Distribution Analysis on the Deposition Mechanism Complexity of the Organic Material of Kidney Stone. J Biomed Phys Eng. 2020;10(3):273-282. doi: 10.31661/jbpe.v0i0.1104.

\section{Keywords}

Kidney calculi; Spatial Analysis; Minerals

\section{Introduction}

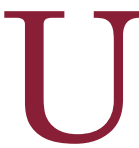

rolithiasis is a disease that occurs in the kidney and urinary tract due to the formation of solid materials being similar stones. An unbalanced interstitial fluid, which was affected by the metabolic factors of the human body, lifestyle, and the environment, can increase the concentration of the urine which triggers the formation of kidney stones [1,2]. This disease has been known since the ancient Greece where the recent number of cases reaches 1-5\% in Asia, 5-9\% in Europe, $13 \%$ in North America, $20 \%$ in Saudi Arabia which made it the third
${ }^{1} \mathrm{MSc}$, Nuclear Physics and Biophysics Research Division, Faculty of Mathematics and Natural Sciences, Institut Teknologi Bandung J. Ganesha 10 Bandung 40132, Indonesia

${ }^{2} \mathrm{PhD}$, Nuclear Physics and Biophysics Research Division, Faculty of Mathematics and Natu-

ral Sciences, Institut

Teknologi Bandung J. Ganesha 10 Bandung 40132, Indonesia

${ }^{3} \mathrm{PhD}$, Magnetic and Pho tonic Physics Research

Division, Faculty of Mathematics and Natural Sciences, Institut Teknologi Bandung Jl. Ganesha 10 Bandung 40132, Indonesia

*Corresponding author: Y. Warty

Department of Physics,

Faculty of Mathematic

and Natural Sciences,

Institut Teknologi Band-

ung, Jalan Ganesa 10,

Bandung, West Java,

40132, Indonesia

E-mail: yuniwarty@s.itb. ac.id

Received: 7 January 2019 Accepted: 5 February 2019 
largest urology disease in the world [3-5]. The comparison of cases based on gender bears a ratio of 2:1 between males and females, respectively. Meanwhile, the rates of recurrence for men and women are $70 \%-80 \%$ and $47 \%$ - $60 \%$, respectively [6]. The ratio of patients with kidney stones to the total population was 1:272 in 2017.

The kidney stones were formed initially by a nucleation process of the urinary mineral due to the presence of supersaturation in the process of urine production. After that, the nuclei will accumulate to form an aggregate growing to a pathological size of several tens micrometers [7]. The size continues in order to grow to the size of millimeters or centimeters until a stone is formed [8]. In general, the composition of kidney stones consists of crystals or organic material with a typical comparison of each patient. Commonly, organic and crystalline materials found are calcium oxalate, calcium phosphate, struvite, uric acid and cystine [9]. Besides of that, 82 compounds have been found in kidney stones, but only 7 of them each account for more than $1 \%$ of kidney stone compounds. The numbers in kidney stones are around $34 \%$ and $44 \%$ for monomineral and duamineral, respectively [10].

There are many methods used to analyze kidney stones, but in this study FTIR-ATR and SEM-EDS were used for quantitative analysis and morphology of kidney stones. Infrared spectroscopy is very effective for quantitatively determining minerals contained in kidney stone because this method is quite sensitive to changes in composition [11, 12]. SEM-EDS is the most widely used instrument for morphological studies and percentage information on element composition of kidney stones [13]. Some studies reported the results of characterization of kidney stones using the FTIR and SEM-EDS methods with samples in the form of powder $[14,15]$. Even though it is very important to review each layer of stone because the composition and distribution of elements in various layers of stone can show metabo- lism in the formation phase of kidney stones. Furthermore, this will be very beneficial for treatment in patients [16-18].

In this study, we have used the FTIR and SEM-EDS methods to study the composition and morphology of each stone layer by not changing the shape and arrangement of the layers of stone. Thus, the study specifically aims to provide insight into the pathology of kidney stones that will contribute to prevention and treatment planning.

\section{Material and Methods}

\section{Material}

This analytical study, was approved by the ethics committee of RSHS Bandung. Thirty six kidney stones were provided from the Urology Department of Hasan Sadikin Hospital (RSHS) Bandung, West Java, Indonesia. Owing to the time and financial restriction, only five out of thirty six kidney stones were selected to be used as samples for this study. The selection of samples was performed by considering the variation in shape and color, as shown in Figure 1.

The sample stones were washed by aquabides to cleanse the stones from the residue of the biological cells such as mucus, blood and bacteria $[4,11]$. Then, the samples were cut on the longitudinal axis using a low speed cutting tool with a thickness of $1 \mathrm{~mm}$. In the final stage, the samples were dried in an oven at a constant temperature of $50^{\circ} \mathrm{C}$ for 48 hours and stored in a sterilized environment.

\section{Methods}

The composition, morphology and percentage of elements were reviewed for each sample. The measurements at each layer were performed at 5 measurement points which were started from the inner layer of kidney stones to the outside and then have been numbered from 1 to 5 (Table 1). The composition of the kidney stones was obtained using Fourier Transform Infrared (FTIR) method. In principle, 


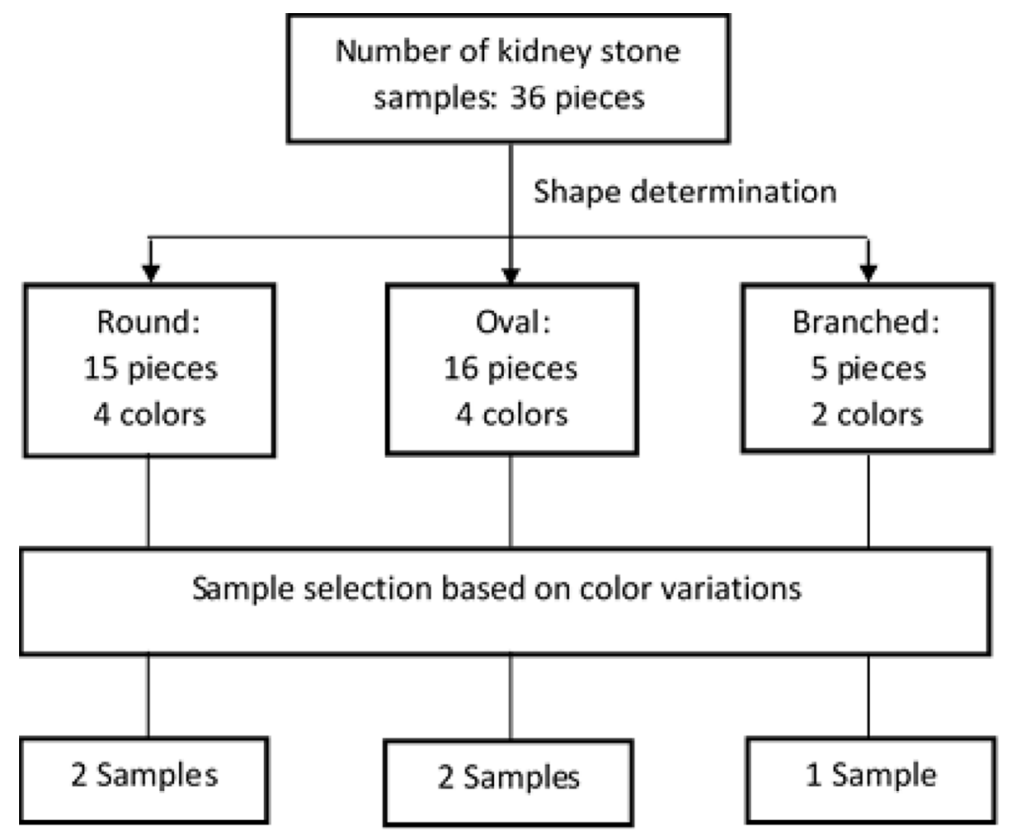

Figure 1: Flowchart determining the number of samples.

the IR spectrum from the stones was captured by the FTIR machine and created a molecular fingerprint that represents the absorption and transmission of each molecule. The fingerprint peak size directly correlates with the quality and quantity of chemicals [19]. Meanwhile, the morphology and percentage of elements from kidney stones were obtained using SEMEDS.

The FTIR measurements were performed using FTIR-ATR Alpha-P by Bruker which spectra were recorded in the range of $500 \mathrm{~cm}^{-1}$ $-4000 \mathrm{~cm}^{-1}$. This tool works with the measurement technique of attenuated total reflectance (ATR) with transparent diamond as an internal reflection element (IRE). The measurement process starts by measuring absorption without a sample above the crystal surface (background). Then, a sample was placed on the surface of the IRE crystal. The identification of the obtained infrared absorption peaks was carried out using OPUS 7.2 software which was integrated in the FTIR-ATR Alpha-P. The peak of the spectrum provides information on the chemical bonds in a compound or element found in the kidney stones. The type of the kidney stone was determined by matching and comparing the infrared absorption peaks with the reference spectrum.

Kidney stone morphology was observed using SEM Hitachi SU3500 and JEOLJSM-6510 LA. Hitachi SU3500 was used to measure sample 2, 4, and 5 with a magnification of 500-15000 times. JEOL-JSM-6510 LA was used to measure samples 1 and 3 with 500 to 2000 times magnification. Prior to the scan, the samples were coated with gold $(\mathrm{Au})$ in the vacuum to make the samples more conductive. Furthermore, the scanning of the morphology of the kidney stones was performed at the 5 measurement points, as illustrated in Table 1 . The image was analyzed by observing and comparing the crystal shape to the reference. The measurement of the percentage of the constituent elements was carried out after the scanning the morphology of the stone in order to retain the same observation points.

\section{Results}

Table 1 shows the specifications of the five kidney stone samples. The diameters of the stones were 16, 19, 24, 28 and $32 \mathrm{~mm}$. The 
Table 1: Physical appearance and compound of kidney stone.

\begin{tabular}{|c|c|c|c|c|}
\hline Sample & $\begin{array}{c}\text { Picture of kidney } \\
\text { stones }\end{array}$ & $\begin{array}{l}\text { The cross-sectional } \\
\text { layers of kidney stone }\end{array}$ & Colors & Compounds \\
\hline US 1 & & & Blackish brown & Calcium oxalate monohydrate \\
\hline US 2 & & & Dirty white & Struvite \\
\hline US 3 & & & Whitish brown & $\begin{array}{c}\text { Ammonium ion calcium oxalate } \\
\text { monohydrate }\end{array}$ \\
\hline US 4 & & & Dark brown & $\begin{array}{l}\text { Mixture of calci-um oxalate } \\
\text { mono-hydrate and calci-um } \\
\text { phosphate }\end{array}$ \\
\hline US 5 & & & Yellow & Uric acid \\
\hline
\end{tabular}

appearance of the cross-sectional layers of kidney stone was observed like a tree trunk cambium with a different color for each layer.

\section{a. Characterization of kidney stones with FTIR-ATR}

The samples were identified into several types of stone based on the FTIR-ATR spectrum, as shown in Table 1. Figure 2 shows the infrared absorption spectrum in the sample.
The graph illustrates the relationship between the absorption intensity (a.u) and the wave number $\left(\mathrm{cm}^{-1}\right)$. The infrared absorption spectrum in each layer in the same stone shows the same peak value, as shown in Figure 2(a). On the other hand, the infrared absorption in all samples showed different values indicating the different types of stone. The FTIR Spectral data of urinary stones was shown in Table 2.

Calcium oxalate monohydrate was char- 

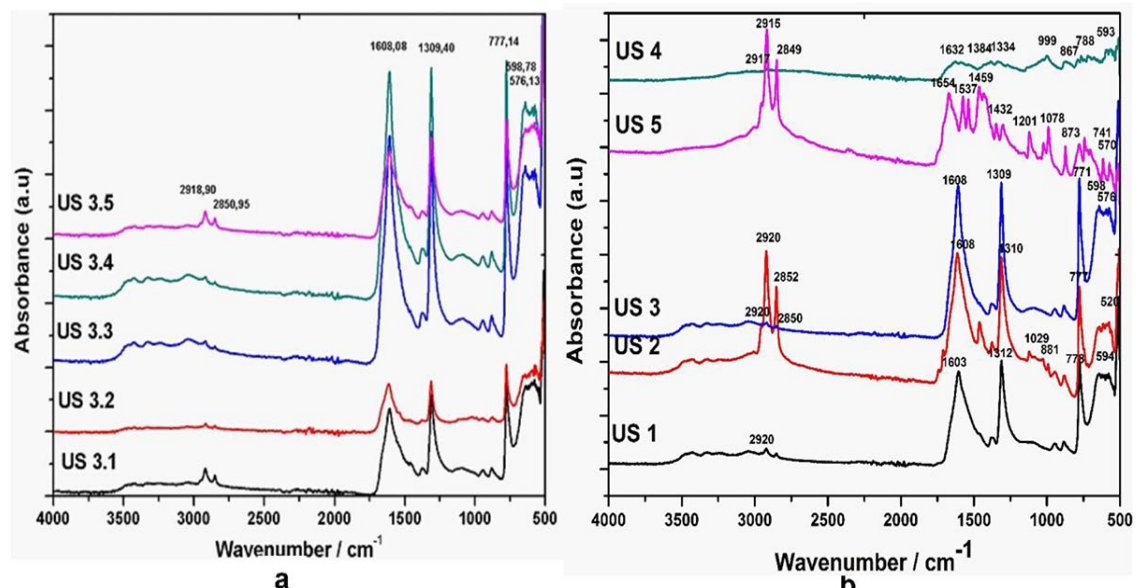

Figure 2: (a) FTIR spectrum of kidney stone samples (number 3) in each layer, (b) FTIR spectrum of five kidney stone samples in the core layer (1).

Table 2: FTIR Spectral data of urinary stones [19-26].

Wave Numbers $\left(\mathrm{cm}^{-1}\right)$

\begin{tabular}{|c|c|c|c|c|c|}
\hline Sample 1 & Sample 2 & Sample 3 & Sample 4 & Samnle 5 & Tentative assignments \\
\hline & 520,90 & & & & C-O stretching \\
\hline \multirow[t]{2}{*}{594,53} & 520,90 & 576,13 & 593,08 & 570,46 & O-C-O Bending \\
\hline & & 698,78 & & & O-H Bending \\
\hline \multirow[t]{6}{*}{777,90} & 777,15 & 777,14 & 788,41 & 741,74 & C-H Bending \\
\hline & & & 887,68 & 873,38 & P-O sretching \\
\hline & 831,37 & & & & C-C stretching \\
\hline & & & & 992 & C-N stretching \\
\hline & 1029,09 & & 999,32 & 1078,63 & P-O sretching \\
\hline & & & & 1201,78 & Ring vibration \\
\hline \multirow[t]{6}{*}{1312,23} & 1310,78 & 1309,40 & 1334,20 & 1302,28 & C-O stretching \\
\hline & & & & 1344,75 & $\mathrm{~N}-\mathrm{H}$ stretching \\
\hline & & & 1384,33 & & C-N stretching \\
\hline & & & & 1432,54 & $\mathrm{O}-\mathrm{H}$ bending \\
\hline & & & & 1459,41 & $\mathrm{P}=\mathrm{O}$ stretching \\
\hline & & & & 1537,27 & $\mathrm{~N}-\mathrm{O}$ stretching \\
\hline \multirow[t]{3}{*}{1603,84} & 1688,04 & 1608,08 & 1632,04 & 1654,75 & $\mathrm{C}=0$ stretching \\
\hline & 2853,29 & 2850,95 & & 2849,47 & $\mathrm{~N}-\mathrm{H}$ stretching \\
\hline & 2920,24 & 2918,90 & & 2915,99 & $\mathrm{NH}_{4}^{+}$stretching \\
\hline
\end{tabular}


acterized by four sharp peaks between wave number $1600 \mathrm{~cm}^{-1}-777 \mathrm{~cm}^{-1}$. In sample 1 , the absorption peak appears in the wave number of $1603.84 \mathrm{~cm}^{-1}(\mathrm{C}=\mathrm{O}$ stretching $) ; 1312.23$ $\mathrm{cm}^{-1}$ (C-O stretching); $777.90 \mathrm{~cm}^{-1}$ (C-H Bending); and $594 \mathrm{~cm}^{-1}$ (O-C-O Bending). Struvite stones in sample 2's IR spectrum were very easily characterized by the presence of a peak in $1029.09 \mathrm{~cm}^{-1}$ which shows $\mathrm{PO}_{4}^{3-}$ ions. Other absorption areas in sample 2 were 2920.24 $\mathrm{cm}^{-1}-2853.29 \mathrm{~cm}^{-1}$ (N-H stretching) indicating the presence of $\mathrm{NH}_{4}^{+}$(ammonium ion); $1688.04 \mathrm{~cm}^{-1}(\mathrm{C}=\mathrm{O}$ stretching $) ; 1310.78 \mathrm{~cm}^{-1}$ (C-O stretching); $831.37 \mathrm{~cm}^{-1}$ (C-C stretching); $777.15 \mathrm{~cm}^{-1}$ (C-H Bending); and 520.90 $\mathrm{cm}^{-1}$ (O-C-O Bending). The absorption area between $1608.08 \mathrm{~cm}^{-1}-777 \mathrm{~cm}^{-1}$ in sample 3 showed that the stone was a calcium oxalate monohydrate stone; however, with the peak of $2918.90 \mathrm{~cm}^{-1}$ and $2850.95 \mathrm{~cm}^{-1}$ (N-H stretching) indicated the presence of $\mathrm{NH}_{4}^{+}$(ammonium ion); therefore the stone was included in the type of ammonium ion calcium oxalate monohydrate. The mixture of calcium oxalate and calcium phosphate in sample 4 was shown by a high absorption area peak at $999.32 \mathrm{~cm}^{-1}$ (P-O stretching) which means that there were $\mathrm{PO}_{4}{ }^{3-}$ ions in the absorption area. A peak which characterizes calcium oxalate kidney stone type was also found in the sample. The peaks are shown at $1632.04 \mathrm{~cm}^{-1}(\mathrm{C}=\mathrm{O}$ stretching $)$; $1384.33 \mathrm{~cm}^{-1}$ (C-N stretching); $1334.20 \mathrm{~cm}^{-1}$ (C-O stretching); $887.64 \mathrm{~cm}^{-1}$ (C-C stretching); $788.41 \mathrm{~cm}^{-1}$ (C-H Bending); $593.08 \mathrm{~cm}^{-1}$ (O-C-O Bending). The area of absorption peaks in sample 5 included uric acid kidney stones. The absorption of intensity in this type of stone was also characterized by the presence of an absorption area at $992 \mathrm{~cm}^{-1}$ (C-N stretching), $1459.41 \mathrm{~cm}^{-1}$ ( $\mathrm{P}=\mathrm{O}$ stretching).

\section{b. Characterization of kidney stones by SEM-EDS}

The classification of kidney stone from the crystal shape was performed by SEM as shown in Figure 3. The variations of the morphology of calcium oxalate monohydrate crystals were very low. The boundary of the crystal was
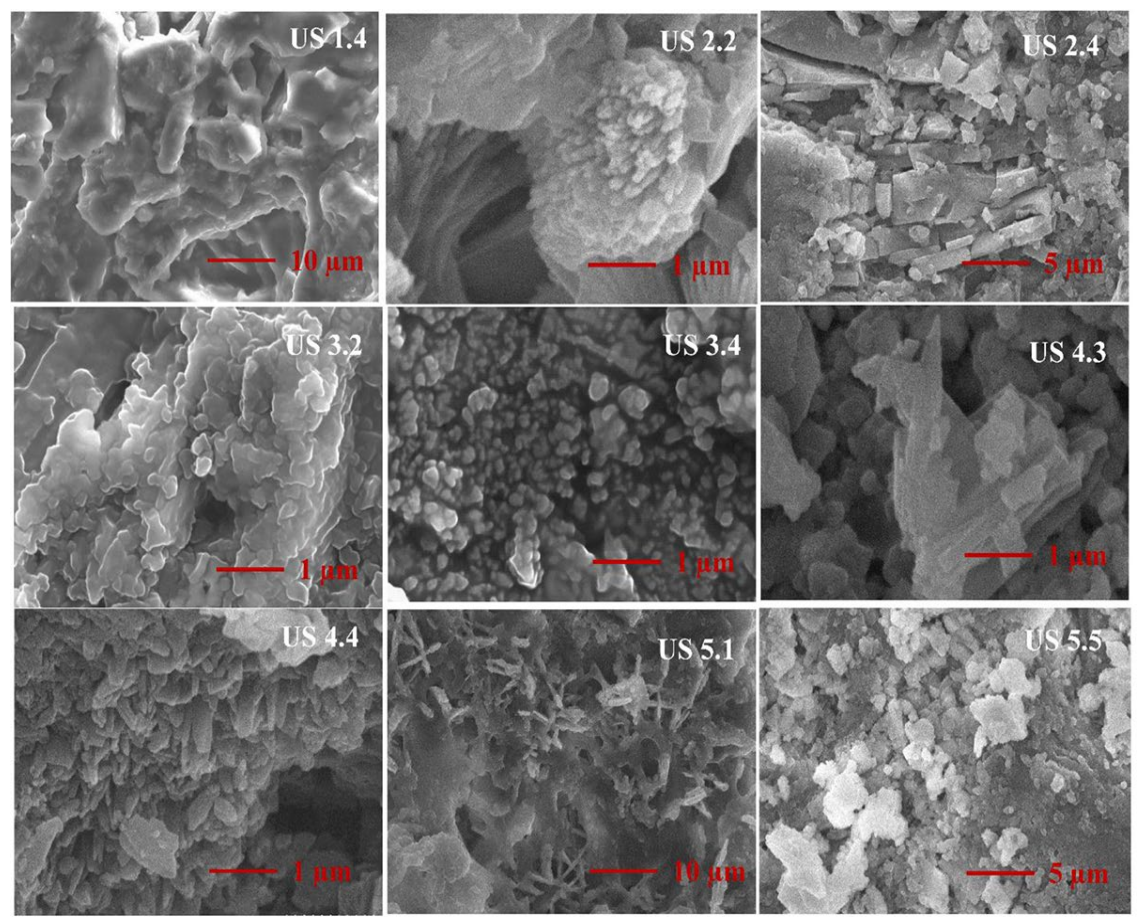

Figure 3: Morphology of kidney stones in several kidney stones. 
not visible because the size of the boundary is quite small (Figure 3 US 1.4). COM was also often indicated by a round shape at the end of the crystal or an ovoid shape [27]. Struvite crystals have a pentahedral, rectangular and prismatic morphology [28, 29]. In Figure 3 US 2.2 and US 2.4, it was observed that rosette shaped ammonium crystals are organized in concentric laminates forming conglomerates. The presence of ammonium ion crystals in kidney stones is found in morphological forms such as rosettes or spherulites or column shapes [30]. These characteristics were not found in Figure 3 US 3.2 to 3.4. Calcium phosphate crystals are usually found among the main components of kidney stones. The mixture of calcium oxalate monohydrate with calcium phosphate (Figure 3 US 4.3 and 4.4) was morphologically characterized by rectangular crystal shapes. This type of kidney stone usually has a small crystal with diameter of 5 $\mu \mathrm{m}$ to $10 \mu \mathrm{m}$ and a spherulitic shape such as a needle or plate arranged in a circular radial manner [31]. Uric acid has various morphologies such as rectangles and diamond shapes [27]. Furthermore, in the results of this study, UA stone types (Figure 3 US 5.1 and US 5.5) have prismatic and fibrillar forms.
The number of atoms in the molecule was determined by EDS. Each sample layer showed different elements and distributions as shown in Figure 4. The main elements of $\mathrm{COM}$ stones are $\mathrm{O}, \mathrm{C}$, and $\mathrm{Ca}$. Other elements found such as $\mathrm{Na}, \mathrm{Si}$ and $\mathrm{P}$ had relatively small amounts. Element $\mathrm{C}$ is distributed to all layers, especially in COM types (samples 1 and 3) where the number of element $\mathrm{C}$ was two times higher than COM mixed with calcium phosphate, as shown in Figure 4. The distribution of the main elements $\mathrm{O}, \mathrm{Mn}, \mathrm{N}$, and $\mathrm{P}$, in struvite was apparent in all layers of stone with a nearly even percentage. The struvite stone was also mixed with small components such as $\mathrm{C}$, $\mathrm{Na}, \mathrm{Ca}$, and $\mathrm{K}$. The number of $\mathrm{N}$ elements in the struvite stone was 3 times more than other types of stone (samples 4 and 5). The main elements in UA stones are $\mathrm{C}, \mathrm{N}$, and $\mathrm{O}$ which have the higher number than $\mathrm{Na}, \mathrm{Si}, \mathrm{Ca}$, and $\mathrm{P}$. The $\mathrm{O}$ element was 2 times more compared to COM and struvite stones. Smaller elements in UA stones were concentrated in certain areas and were not spread throughout the layers of stone.

\section{Discussion}

The development of kidney stones requires

\begin{tabular}{|c|c|c|c|c|c|c|c|}
\hline \multicolumn{7}{|c|}{ Percent Atomic Rations Abundance } \\
\hline $60-80$ & $40-59$ & $20-39$ & $10-19$ & $5-9$ & $1-4$ & $0.2-0.9$ & 0 \\
\hline & & & & & & & \\
\hline
\end{tabular}

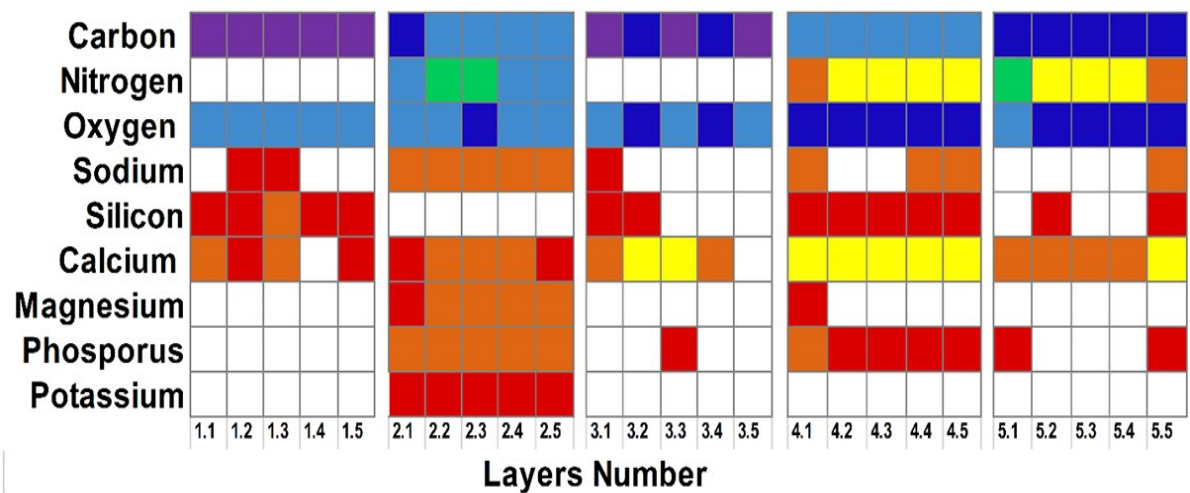

Figure 4: Percentage of constituent elements in each layer of kidney stone. 
crystal formation in tubular fluid followed by crystal retention and accumulation in the kidneys [32]. The biochemical studies of blood and urine are not enough to reveal and identify the exact causes of nucleation and stone growth. However, it was obtained by analysing the structure and composition of the stone after the patient's surgery. The main components of kidney stones were the scientific basis for the choice of management of clinical and preventive measures. The identification of the small components number located in the nucleus of kidney stones and other layers cannot be ignored, since this information can indicate specific nucleation processes or stone growth. There are many methods to analyse kidney stones such as the chemical analysis and physical analysis. The chemical and physical analysis have provided valuable information for the etiology and pathology of kidney stones. In this study FTIR-ATR and SEMEDS methods were used to study the composition and morphology of each layer of stone by not changing the shape and arrangement of the layers of stone.

The FTIR-ATR spectrometer has high sensitivity and simple analysis for the molecular composition of small samples. This tool is widely used to characterize kidney stones in powder samples [17-24]. Each point reviewed in the sample will provide specific information [27]. The main component of urinary tract stones is calcium oxalate with ratio of $75-90 \%$ of kidney stones followed by calcium phosphate or uric acid [26]. Our results showed that calcium oxalate was the main component that made up kidney stones and the rest was composed of other elements such as phosphorus, magnesium, ammonium ions. The high percentage of calcium oxalate was as an elementary component of kidney stone due to the presence of mineral deposition in the kidneys owing to supersaturation.

The two types of calcium oxalate that often appear are calcium oxalate monohydrate (whewellite) and dihydrate (weddellite). In the characterization of kidney stones, the second type of oxalate often appears together in various proportions. Infrared identification of this type has absorption peaks in the area of 36003000, 1400-1300, and 800-400 $\mathrm{cm}^{-1}$ [24]. Struvite (magnesium ammonium phosphate hexahydrate) is formed due to a urinary tract infection. At a $\mathrm{pH}$ value of 7.5, struvite supersaturation will occur even though magnesium and phosphate in the urine is still within normal limits. Phosphate and magnesium in kidney stones have a specific infrared spectrum $\left(1010,2370,760,572 \mathrm{~cm}^{-1}\right)$. The uric acid kidney stones have infrared spectrum in 1020 , 1592, 1440, 1403, 1350, 1312, 1123, 993, 878, $783,745,705,620,578,525$ and $475 \mathrm{~cm}^{-1}$ [24]. The formation of uric acid stones is influenced by insulin resistance, molecular factors, genetics, urine $\mathrm{pH}$, uric acid metabolism, and excretion [28]. Low urine $\mathrm{pH}$ is the main factor in the formation of uric acid stones.

In the results of our study, the kidney stones with FTIR have been well-characterized. This was indicated by a sharp absorption peak in each molecule. However, the same absorption peaks are found in each layer. Besides that, the constituent components of kidney stones in small numbers were also not detected. Small amounts of kidney stone organic components are difficult to detect by many methods such as FTIR. Therefore, another method is needed to detect these small components [26].

SEM provides information of the main components of stone from its morphology, but many of them found the same morphology form of several types of stone, for example, calcium oxalate monohydrate and brushite have an ovoid or rectangular shape. In addition, ammonium and uric acid types also have a similar shape to rosettes [29, 31]. The same thing is also shown by the results of this study. This similarity occurs because there are similar components in some kidney stones that have been observed. Because of the similarity in morphology, identification can be done using EDS to detect single elements with atomic 
numbers on carbon. Our results showed that minor quantities of crystals or organic compounds can be identified by high accuracy using scanning electron microscopy with energy dispersive X-ray.

The distribution of elements in each layer of kidney stones was different (Figure 4). A higher percentage composition element indicated the main constituent component of the stone. The number of minor components was also found in each layer such as silicon found in US 1, US 4 and US 5 stone samples. The presence of silicon in the stone is due to drugs [30]. This mineral is not found in every layer as shown in US 5 only found in layers 2 and 5 . In addition to these minerals, other minerals also do not always exist in each layer. For example, mineral sodium at US 1 was found in layers 2 and 3, US 3 only at layer 1, US 4 at layers 1, 4, 5 and US 5 only at layer 5 . The difference in composition in each layer shown in this study provided insight new on pathological kidney stones. In addition, the large contribution will be very useful by studying the quantization of kidney stone layers. Future studies in our group will aim to quantify the layers of kidney stones.

\section{Conclusion}

Pathogenesis of kidney stones can be understood by analyzing chemical composition, morphology, and composition of stone elements. Analysis of elemental components with FTIR-ATR can show the main minerals that make up the stones. However, this is less sensitive to minerals in small quantities so that absorption peaks in each layer are the same. Meanwhile, SEM-EDS shows that each layer in kidney stones has a different percentage and composition of elements. This indicates that each layer has a different pathology. This study provides an objective basis for further research in understanding the pathology of kidney stone layers to make decisions in medicine, prevention strategies and management of kidney stones.

\section{Acknowledgment}

The author expresses his gratitude to the Ministry of Research, Technology and Higher Education for funding this research with the FMIPA DIKTI 2018 Grant scheme. Decree 01 / E / KPT / 2018 and Contract Number 127 / SP2H / PTNBH / DRPM / 2018.

\section{Conflict of Interest}

None

\section{References}

1. Fukuhara $H$, Ichiyanagi 0 , Kakizaki $H$, Naito $S$, Tsuchiya $\mathrm{N}$. Clinical relevance of seasonal changes in the prevalence of ureterolithiasis in the diagnosis of renal colic. Urolithiasis. 2016;44:529-37. doi: 10.1007/ s00240-016-0896-3. PubMed PMID: 27314408. PubMed PMCID: PMC5063892.

2. Aslin Shamema A, Thanigai Arul K, Senthil Kumar $\mathrm{R}$, Narayana Kalkura S. Physicochemical analysis of urinary stones from Dharmapuri district. Spectrochim Acta A Mol Biomol Spectrosc. 2015;134:4428. doi: 10.1016/j.saa.2014.05.088. PubMed PMID: 25033236.

3. Modlin M. A history of urinary stone. S Afr Med J. 1980;58:652-5. PubMed PMID: 6999641.

4. Jing Z, GuoZeng W, Ning J, JiaWei Y, Yan G, Fang $Y$. Analysis of urinary calculi composition by infrared spectroscopy: a prospective study of 625 patients in eastern China. Urol Res. 2010;38:111-5. doi: 10.1007/s00240-010-0253-X.

5. Selvaraju R, Thiruppathi G, Raja A. FT-IR spectral studies on certain human urinary stones in the patients of rural area. Spectrochim Acta $A \mathrm{Mol}$ Biomol Spectrosc. 2012;93:260-5. doi: 10.1016/j. saa.2012.03.028. PubMed PMID: 22484261.

6. Sohgaura A, Bigoniya P. A review on epidemiology and etiology of renal stone. Am J Drug Discov Dev. 2017;7:54-62.

7. He J-Y, Deng S-P, Ouyang J-M. Morphology, particle size distribution, aggregation, and crystal phase of nanocrystallites in the urine of healthy persons and lithogenic patients. IEEE transactions on nanobioscience. 2010;9:156-63. doi: 10.1109/ tnb.2010.2045510.

8. Khan SR, Kok DJ. Modulators of urinary stone formation. Front Biosci. 2004;9:1450-82. PubMed PMID: 14977559.

9. Selvaraju R, Raja A, Thiruppathi G. Chemical composition and binary mixture of human urinary stones using FT-Raman spectroscopy method. Spectrochim Acta A Mol Biomol Spectrosc. 2013;114:6507. doi: 10.1016/j.saa.2013.05.029. PubMed PMID: 


\section{5}

10. Kocademir M, Baykal A, Kumru M, Tahmaz ML. Structural characterization and vibrational studies of human urinary stones from Istanbul, Turkey. Spectrochimica Acta Part A: Molecular and Biomolecular Spectroscopy. 2016;160:1-7. doi: 10.1016/j. saa.2016.01.055.

11. Zarse CA, McAteer JA, Sommer AJ, Kim SC, Hatt EK, Lingeman JE, et al. Nondestructive analysis of urinary calculi using micro computed tomography. BMC Urol. 2004;4:15. doi: 10.1186/1471-2490-4-15. PubMed PMID: 15596006. PubMed PMCID: PMC544194.

12. Rahiman M, Vipin C, Bernhardt V, AP M, D'souza N. Mineral composition of urinary stones-Quantitative analysis by FTIR Spectroscopy. Indian Journal of Research. 2014;3:130-32.

13. Tokuhara Y, Shukuya K, Tanaka M, Mouri M, Ohkawa $\mathrm{R}$, Fujishiro $\mathrm{M}$, et al. Detection of novel visible-light region absorbance peaks in the urine after alkalization in patients with alkaptonuria. PLoS One. 2014;9:e86606. doi: 10.1371/journal.pone.0086606. PubMed PMID: 24466168. PubMed PMCID: PMC3900575.

14. Selvaraju R, Thiruppathi G, Raja A. FT-IR spectral studies on certain human urinary stones in the patients of rural area. Spectrochim Acta $\mathrm{A} \mathrm{Mol}$ Biomol Spectrosc. 2012;93:260-5. doi: 10.1016/j. saa.2012.03.028. PubMed PMID: 22484261.

15. Kanchana G, Sundaramoorthi P, Jeyanthi G. Biochemical analysis and FTIR-spectral studies of artificially removed renal stone mineral constituents. Journal of Minerals and Materials Characterization and Engineering. 2009;8:161-70. doi: 10.4236/ jmmce.2009.82014.

16. Evan AP. Physiopathology and etiology of stone formation in the kidney and the urinary tract. Pediatr Nephrol. 2010;25:831-41. doi: 10.1007/s00467-0091116-y. PubMed PMID: 19198886. PubMed PMCID: PMC2839518.

17. Ratkalkar VN, Kleinman JG. Mechanisms of Stone Formation. Clin Rev Bone Miner Metab. 2011;9:18797. doi: 10.1007/s12018-011-9104-8. PubMed PMID: 22229020. PubMed PMCID: PMC3252394.

18. Mandel I, Mandel N. Structure and compositional analysis of kidney stones. Urinary Stone Disease: Totowa: Humana Press; 2007. p. 69-81.

19. He Z, Jing Z, Jing-Cun Z, Chuan-Yi H, Fei G. Compositional analysis of various layers of upper urinary tract stones by infrared spectroscopy. Exp Ther Med. 2017;14:3165-9. doi: 10.3892/etm.2017.4864. PubMed PMID: 28912866. PubMed PMCID: PMC5585751.

20. Sekkoum K, Cheriti A, Taleb S, Belboukhari N. FTIR spectroscopic study of human urinary stones from $\mathrm{El}$ Bayadh district (Algeria). Arabian Journal of Chemis- try. 2016;9:330-4. doi: 10.1016/j.arabjc.2011.10.010.

21. Khaskheli MH, Sherazi STH, Ujan HM, Mahesar SA. Transmission FT-IR spectroscopic analysis of human kidney stones in the Hyderabad region of Pakistan. Turkish Journal of Chemistry. 2012;36:477-83.

22. Manzoor MAP, Mujeeburahiman M, Rekha PD. Electron probe micro-analysis reveals the complexity of mineral deposition mechanisms in urinary stones. Urolithiasis. 2019;47:137-48. doi: 10.1007/s00240018-1052-z. PubMed PMID: 29504067.

23. Sofia P, Ionescu I, Rodica G, Anisoara P. The use of infrared spectroscopy in the investigation of urolithiasis. Revista română de medicină de laborator. 2010;18:67-77.

24. Carmona P, Bellanato J, Escolar E. Infrared and Raman spectroscopy of urinary calculi: A review. Biospectroscopy. 1997;3:331-46. doi: 10.1002/(sici)15206343(1997)3:5<331::aid-bspy2>3.0.c0;2-5.

25. Estepa L, Daudon M. Contribution of Fourier transform infrared spectroscopy to the identification of urinary stones and kidney crystal deposits. Biospectroscopy. 1997;3:347-69. doi: 10.1002/(sici)15206343(1997)3:5<347::aid-bspy3>3.0.co;2-\#.

26. Khan SR, Hackett RL. Identification of urinary stone and sediment crystals by scanning electron microscopy and x-ray microanalysis. J Urol. 1986;135:81825. doi: 10.1016/s0022-5347(17)45868-x. PubMed PMID: 3959214.

27. Oliver KV, Matjiu F, Davey C, Moochhala S, Unwin RJ, Rich PR. Attenuated total reflection Fourier transform infrared (ATR-FTIR) spectroscopy as a bedside diagnostic tool for detecting renal disease biomarkers in fresh urine samples. Optical Diagnostics and Sensing XV: Toward Point-of-Care Diagnostics. 2015;9332:933202. doi: 10.1117/12.2078971.

28. Mukherjee AK. Human kidney stone analysis using Xray powder diffraction. J Indian Inst Sci. 2014;94:3544.

29. Marickar YF, Lekshmi P, Varma L, Koshy P. Elemental distribution analysis of urinary crystals. Urol Res. 2009;37:277-82. doi: 10.1007/s00240-009-0203-7.

30. Dessombz A, Coulibaly G, Kirakoya B, Ouedraogo RW, Lengani A, Rouziere $S$, et al. Structural elucidation of silica present in kidney stones coming from Burkina Faso. C R Chim. 2016;19:1573-9. doi: 10.1016/j.crci.2016.06.012.

31. Zhang GN, Xia ZY, Ouyang JM, Kuan L. Study on nano-and microcrystallites in urines of uric acid stone patients. Adv Mat Res. 2013;655:1927-30. doi: 10.4028/www.scientific.net/amr.655-657.1927.

32. Verkoelen CF, Verhulst A. Proposed mechanisms in renal tubular crystal retention. Kidney Int. 2007;72:13-8. doi: 10.1038/sj.ki.5002272. PubMed PMID: 17429341. 